Images in

Cardiovascular

Medicine

Sameer Chadha, MD

Syed Iman Husain, MD

Vijay Shetty, MD

Gerald Hollander, MD

Robert Frankel, MD

Jacob Shani, MD
Section Editor:

Raymond F. Stainback, MD, Department of Adult Cardiology, Texas Heart Institute, 6624 Fannin St., Suite 2480, Houston, TX 77030

From: Cardiology Department, Maimonides Medical Center, 4802 - 10th Ave., Brooklyn, New York 11219

Address for reprints:

Sameer Chadha, MD, 950 - 49th St., \#7E, Brooklyn, NY 11219

E-mail: sameer_n_heart@ yahoo.co.in

(C) 2014 by the Texas Heart ${ }^{\circledR}$ Institute, Houston

\section{Anomalous Origin of Left Main Coronary Artery from Right Sinus of Valsalva}

A 46-year-old man emergently presented after developing chest pain while running for a taxi. He reported no associated shortness of breath, palpitations, or dizziness. His vital signs were stable, and the results of respiratory and cardiovascular examination were normal. An electrocardiogram showed ST-segment elevation in leads $\mathrm{V}_{2}$ through $\mathrm{V}_{6}$ (Fig. 1). An urgent coronary angiogram revealed narrowing at the origin of the left main coronary artery (LMCA) that did not resolve after intracoronary nitroglycerin was administered (Fig. 2). However, there was no evident atherosclerotic disease.

To better characterize the lesion, we performed dual-source, 64-slice computed tomographic scanning (Siemens Medical Solutions USA, Inc.; Mountain View, Calif) with retrospective cardiac gating $(0.6 \times 0.3-\mathrm{mm}$ image slices $)$; postprocessing image reconstruction was done on independent workstations. We found that the LMCA anomalously originated at an acute angle from the right coronary sinus (Fig. 3) and took a malignant course between the proximal ascending aorta and the pulmonary

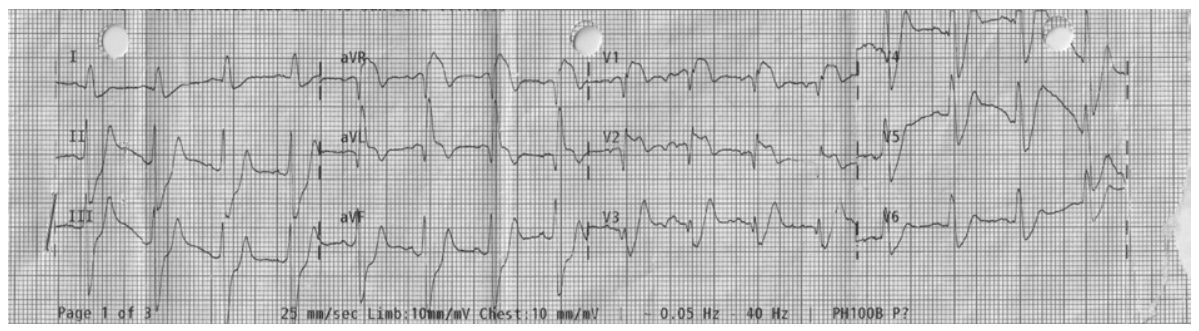

Fig. 1 Electrocardiogram shows ST-segment elevation in leads $V_{2}$ through $V_{6}$.

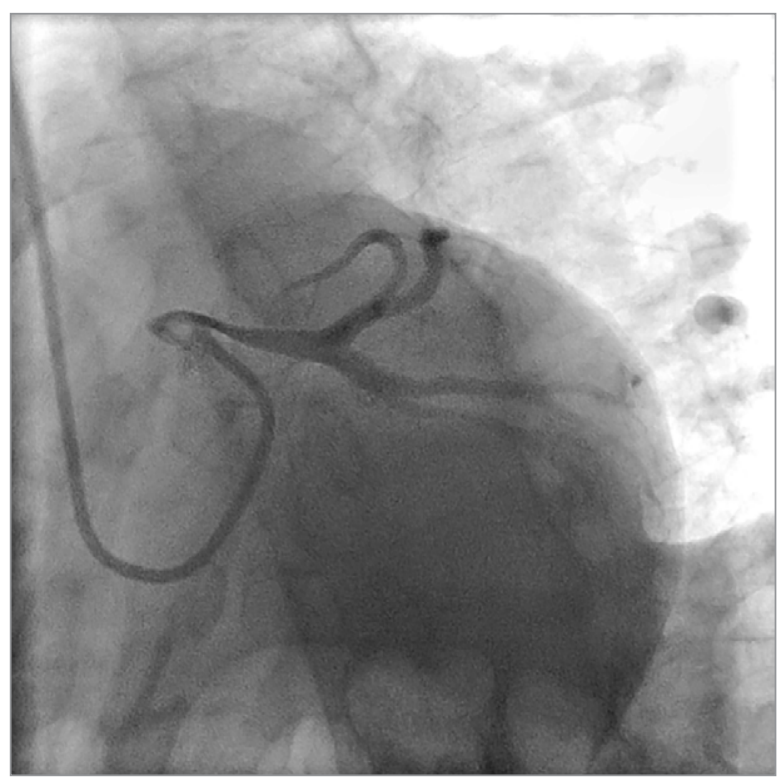

Fig. 2 Coronary angiogram shows narrowing at the origin of the left main coronary artery.

Supplemental motion image is available for Figure 2 

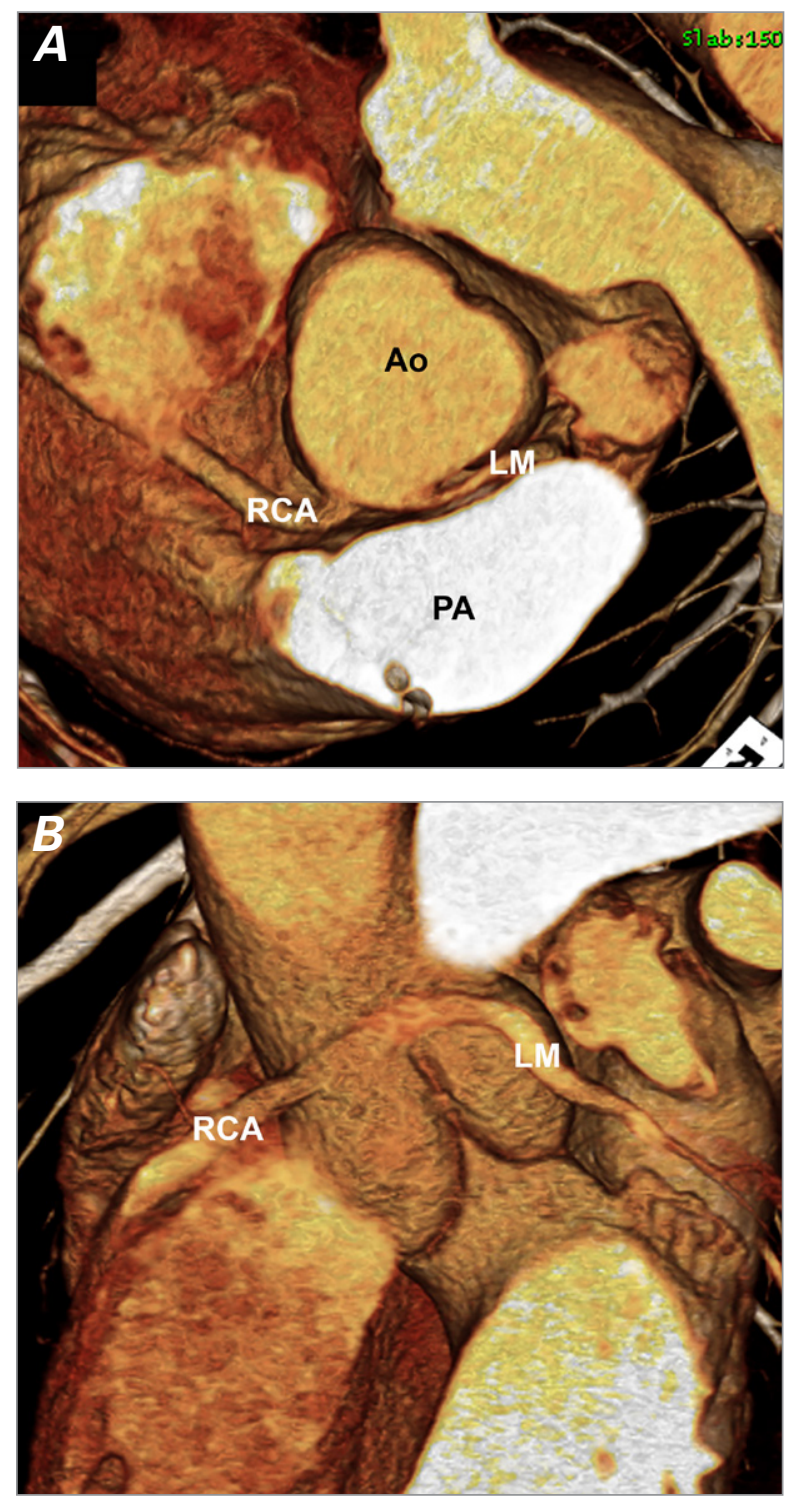

Fig. 3 Computed tomographic angiograms in $\boldsymbol{A}$ ) transverse and B) coronal views show the anomalous origin of the left main coronary artery from the right sinus of Valsalva, along with the right coronary artery.

Ao = aorta; $L M=$ left main coronary artery; $P A=$ pulmonary artery; $R C A=$ right coronary artery

trunk (Fig. 4). The patient was offered corrective surgical repair for this very high-risk anomaly; however, he refused intervention despite aggressive counseling. The rest of his hospitalization was uneventful, and he was discharged in stable condition.

\section{Comment}

Coronary artery anomalies are rare, with an estimated prevalence of around 5\%. ${ }^{1}$ These anomalies vary with respect to number, location, orientation of the ostia, and origin of the coronary arteries. Some anomalies are merely anatomic variants without clinical relevance;

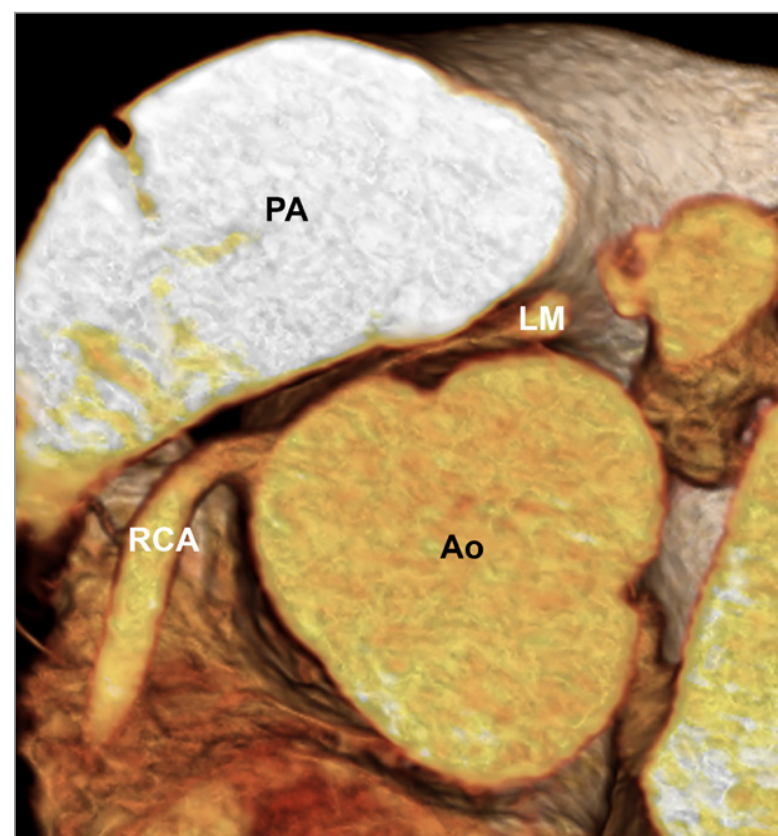

Fig. 4 Computed tomographic angiogram shows the malignant course of the left main coronary artery between the ascending aorta and the pulmonary trunk.

$A o=$ aorta; $L M=$ left main coronary artery; $P A=$ pulmonary artery; $R C A$ = right coronary artery

others can present with chest pain, syncope, or sudden cardiac death. Anomalous origin of a coronary artery from the opposite sinus (the right coronary artery from the left sinus and the LMCA from the right sinus) has the most potential for clinical repercussions, including the risk of sudden cardiac death in young patients. ${ }^{2}$

The origin of the LMCA from the right sinus of Valsalva is extremely rare (approximate prevalence, $0.15 \%$ ). The outward expansion of the aortic root and pulmonary trunk during exertion, in addition to the external compression of the vessel, also increases the angulation at the LMCA ostium, which can result in acute myocardial infarction or sudden cardiac death. ${ }^{3}$

\section{Acknowledgment}

The authors thank Dr. Elliot Borgen for his treatment of the patient and assistance with the manuscript.

\section{References}

1. Angelini P, Velasco JA, Flamm S. Coronary anomalies: incidence, pathophysiology, and clinical relevance. Circulation 2002;105(20):2449-54.

2. Angelini P. Coronary artery anomalies: an entity in search of an identity. Circulation 2007;115(10):1296-305.

3. Barth CW 3rd, Roberts WC. Left main coronary artery originating from the right sinus of Valsalva and coursing between the aorta and pulmonary trunk. J Am Coll Cardiol 1986;7(2):366-73. 